sulphonamides and local painting of lids with sodium sulphacetamide. It was a mistake to assume that just because a disease was of virus origin sulphonamides would not help it.

Major J. O. Oliver said this appeared to be the place to mention penicillin. He had seen a case of cavernous sinus thrombosis with staphylococcal meningitis recover with penicillin. There was a very definite sphere for penicillin in eye work. Major Oliver then called on Dr Rowland Hill for his paper.

Dr. T. Rowland HiLl said that as a physician he would confine his remarks to that portion of Major Cameron's paper in which he so wisely stressed the importance of general medical hygiene. After six months in a rather frowsy static hospital, the recondite wisdom of the Army Council had seen fit to transport him to tropical Nigeria. Here conditions were apt to be primitive. - On one occasion he was forced to live for seven days on a diet consisting of tinned cherries. He paid a high tribute to the negro inhabitants of Nigeria. In spite of some African "trickiness" he had found their financial and other morals the' equal of those he had known in Harley Street. At first he had been posted to a hospital for native troops, where his ignorance of the language had necessitated methods akin to those of a veterinary surgeon. Sanitary conditions were poor in that "white man's grave." At Ibadan, the greatest city of Africa, he had found a town of corrugated iron with only one lavatory to every 3,000 persons. A Welshman had been elected by the local population as its kinglet. Malaria was rife, and the only cows in town were kept behind mosquito netting. Malignant tertian malaria was everywhere with its cerebral, cardiac and intestinal complications. He saw much blackwater fever. Infantile mortality was 50 per cent. among the natives. Intravenous quinine was of ten necessary. Immunisation against yellow fever was fairly effective. Poverty was dreadful. He had not been surprised at the popularity of palm wine as a means of dulling sensibilities. This beneficent liquor was already high in alcohol content, when tapped from the parent palm trunk. Dr. Hill showed the society many pleasing examples of native carvings in some of which could be noted the omnipresent West African condition of umbilical hernia.

\title{
SOME OBSERVATIONS ON A TENDENCY TO NEAR-POINT ESOPHORIA, AND POSSIBLE CONTRIBUTORY FACTORS:
}

BY

\author{
Major D. D. Stenhouse Stewart, R.A.M.C.
}

IN spite of the interest devoted to it by competent observers during the past hundred years, there are many aspects of the physiology of vision which offer scope for further elucidation by simple experiment, mass observation, and statistical analysis.

Medical Officers in Industry and in the Services are better placed than many of their colleagues for purposes of this kind, as it is a simple matter for them to obtain a more general sample of the population to serve as " controls."

The study by Mann and Archibald (Brit. Med. Jl., 1944, Vol. I, p. 387) of a group of 28 women satisfactorily employed in extremely fine work in a factory is an excellent example of opportunities constantly available to extend the limited knowledge and

\footnotetext{
- Received for publication, August 12, 1944.
} 
ascertained fact affecting comfortable near.vision. 'That article confirms the author's opinion that as a generalization-to be accepted with caution-the comfortable binocular performance of sustained close work is associated with an appropriate eyemuscle balance at the working distance, a state of euphoropsia which can be defined as some degree of exophoria in the presence of sufficient power of voluntary convergence, and especially of relative convergence, ample to overcome it.

This fulfits the accepted hypothesis of associated accommodation-convergence innervation, supplemented by additional cortically-controlled impulses of the "convergence centre" in Perlia's nucleus; divergence, independent of the state of accommodation, is believed to arise only by inhibition of convergence (Đuke-Elder, Vol. I, p. 288). If the total of convergence is excessive for the degree of accommodation, a situation manifest as near point esophoria (possible causes of which will be discussed), comfortable clear binocular vision can be attained with the help of convex lenses, whether for correction of actual hypermetropia, assistance of presbyopia, or, in younger people, the restoration of a more natural accommodation-convergence relationship.

A rational basis can be evolved for recognition of the occasion and estimation of the amount of extra "plus " correction to assist the patient, it should displace the routine addition of $+0.50 \mathrm{D}$. sphere binocularly to the carrefully assessed monocular prescription, a habit which can be ascribed to accidental relief attending this practice in chance cases of unrecognised esophoria.

These accidental successes do not warrant the unnecessary expense to a poor patient consequent upon the empirical prescription of $\neq 1$ D. sphere each eye as a placebo to any young emmetrope complaining of discomfort in near work, for it should be remembered that visual symptoms of an indefinite nature ascribed to close work may indicate no more than a desire to escape with honour from circumstances directly or even indirectly related thereto. Furthermore, it is those whose indigence is an index of lower intelligence and weaker psyche who are most lacking in sense of value and sales-resistance when selecting elaborate frames and tinted toric form for their weak lenses. Psychological possibilities deserve particular enquiry when negative ocular findings cast doubt upon a visual basis for the patient's complaint.

Previous experience had led the author to believe that two or more dioptres of exophoria represented the " normal " near point muscle balance (at 33 cms.) with orthophoria as an upper "safety", limit of comfort. When recently he had occasion to measure and record for service purposes the stereo. sense and binocular balance of numbers of men (most of whom had been engaged, without ocular complaint, as architectural or technical draughtsmen, clerks, 
or artists in civilian life), the findings were surprising in certain respects which will be considered.

These men were examined after half an hour's critical test of stereo. sense, by six pairs of stereo. slides of increasing difficulty viewed; each for five minutes, through a stereoscope consisting of a pair of strong plus lenses (without prisms) at a distance of some three inches. Each pair of slides rested on a horizontal sheet of glass illuminated from below : each slide of a pair was independently and freely movable and the candidate adjusted them to suit himself. All but a few of these men had no previous acquaintance with a stereoscope; their tendency to accommodate and therefore to converge for the known position of the object rather than for its distant virtual image was manifest by the necessity to approximate the paired slides in the accomplishment of fusion.

The unusual esophoria in patients examined at a variable interval after supreme and anxious effort of this kind is shown in the following table :-

Near Point Phoria in Prism Dioptres of 125 Service Personnel After Sustained and Dissociated Binocular Effort

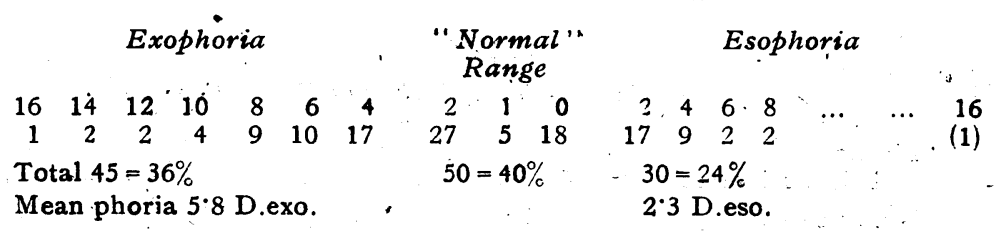

Grand Total :-125 men; mean phoria 2 D.exo.

That the mean phoria corresponds exactly with that which the author accepts as physiological.is due to the large preponderance of findings in the vicinity of this value. The one case with $16 \mathrm{D}$. of esophoria has been ignored, although he showed excellent stereo. sense, to discount any possible prejudice in favour of the hypothesis under examination. It will be agreed that a finding of esophoria in 24 per cent, of a sample selected mainly on their previous efficient performance of close work is outside normal experience, and demands explanation.

It was therefore postulated that an unaccustomed demand upon sustained convergence, especially when this function was dissociated from accommodation by the circumstances of the task, could, in the period of half an hour, create a near point " toric", esophoria of a nature probably transient.

Miss Mann in a, personal communication has informed the author that the subjects of her examinations were tested fairly early in the morning $(9.30$ to $10 \mathrm{a} . \mathrm{m}$.$) , at a time when any abnormal or$ 
"tonic:" esophoria residual from the previous day would probably have disappeared in sleep, and before their customary task at normal distance-would have re-engendered it, if, indeed, such postulate applies to experienced workers.

At the next session of stereo. tests the " resting " near point muscle balance of each man was assessed on first arrival either at 10 a.m., or, after a lunch interval, at 2 p.m.; it was compared with findings taken as each man presented himself within a quarter of an hour of completing the test (or failing by the way) for refraction, phoria, vergence examination, and to have his stereo. capabilities recorded. The results are as follows :-

\section{Near Point Muscle Balance of 73 Men Before and After Test} BEFORE

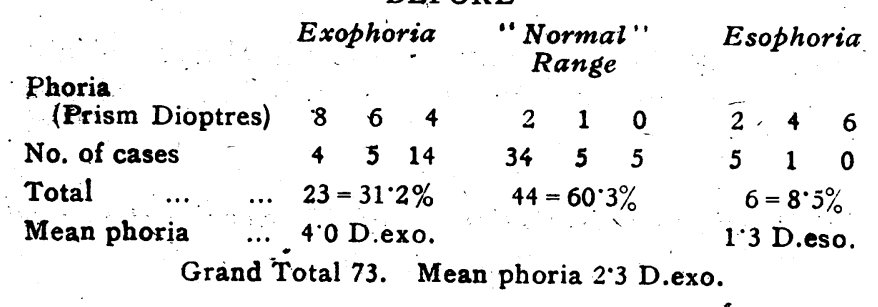

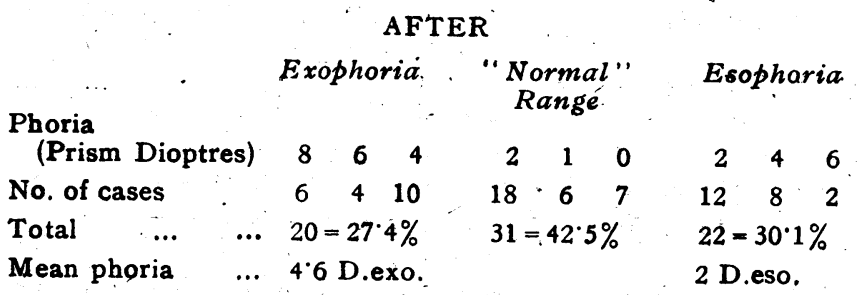

Grand Total 73. Mean phoria 1.0 D.exo.

The mean change of 1.3 prism dioptres in the direction of esophoria is less obviously significant than is the reduced number of those falling within the "normal" range, and the increase of esophores from 8.5 per cent. to $30: 1$ per cent, of the whole. The following table indicates the source and manner of this fluctuation within and between the groups:

\begin{tabular}{|c|c|c|c|c|c|c|c|c|c|}
\hline $\begin{array}{l}\text { Pre-test } \\
\text { Grouping }\end{array}$ & $>2 D$ & $E x \circ$ & phoria & “Nor & 'mal" & $\begin{array}{l}\text { range } \\
\text { Exo. }\end{array}$ & Eso & phori & \\
\hline $\begin{array}{l}\text { Change after } \\
\text { Test }\end{array}$ & & & & 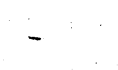 & & & & & $\because$ \\
\hline $\begin{array}{l}\text { Direction } \\
\text { No. of cases }\end{array}$ & $\begin{array}{c}\text { Eso. } \\
14\end{array}$ & $\begin{array}{c}\text { Nil. } \\
3\end{array}$ & $\begin{array}{c}\text { Exo. } \\
6\end{array}$ & $\begin{array}{c}\text { Eso. } \\
23\end{array}$ & $\begin{array}{l}\text { Nil. } \\
10\end{array}$ & $\begin{array}{c}\text { Exo. } \\
11\end{array}$ & $\begin{array}{c}\text { Eso. } \\
6\end{array}$ & $\begin{array}{c}\text { Nil. } \\
0\end{array}$ & $\begin{array}{c}\text { Exo } \\
0\end{array}$ \\
\hline $\begin{array}{l}\text { Amount:- } \\
\quad \text { Mean } \\
\text { (Maximum) }\end{array}$ & $\begin{array}{l}2 \cdot 5 . \mathrm{D} . \\
(5 \mathrm{D} .)\end{array}$ & - & $\begin{array}{l}2 \cdot 7 \mathrm{D} . \\
\text { (5 D.) }\end{array}$ & $\begin{array}{l}2.9 \mathrm{D} . \\
(6 \mathrm{D})\end{array}$ & - & $\begin{array}{l}1 \cdot 7 \mathrm{D} \\
(6 \mathrm{D} .)\end{array}$ & $\begin{array}{l}1.7 \mathrm{D} . \\
\text { (4 D.) }\end{array}$ & $=$ & - \\
\hline
\end{tabular}


Of the increase of ${ }^{\prime} 16$ cases in the esophore group, 14 are contributed from those previously in the normal range, one formerly. showed an exophoria of $3 \mathrm{D}$. and one of $4 \mathrm{D}$. It is noteworthy that every case primarily esophoric showed an increase of esophoria.

The following table shows the original data from which the above analysis is compiled:-

\section{Distribution of 73 Cases According to Phoria in} the "Resting" State

$$
\begin{array}{rrrrr}
\multicolumn{5}{c}{\text { Exo. (-) }} \\
8 & 6 & 5 & 4 & 3 \\
+4 & +4 & +3 & +5 & +4 \\
+3 & 0 & -3 & +4 & +2 \\
+2 & -1 & & +2 & +1 \\
0 & & & +2 & +1 \\
& & & -2 & +1 \\
& -4 & +1 \\
& & & 0 \\
& & & & -5
\end{array}
$$

$$
\begin{array}{lll} 
& & \\
& 2 & \\
+6 & +1 & -1 \\
+6 & +1 & -1 \\
+5 & +1 & -1 \\
+4 & +1 & -1 \\
+4 & 0 & -1 \\
+4 & 0 & -2 \\
+4 & 0 & -2 \\
+4 & 0 & -6 \\
+2 & 0 & \\
+2 & 0 & \\
+2 & 0 & \\
+2 & 0 & \\
+2 & 0 &
\end{array}
$$

Total

$\begin{array}{llllll}\text { Cases } & 4 & 3 & 2 & 6 & 8\end{array}$

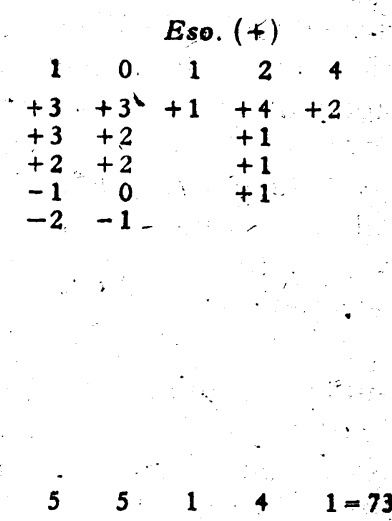

The 'figure' ( + or' - ) represents the direction and number of prism dioptres by which the man's phoria is displaced after close work of the nature described.

\section{Discussion}

It is believed that these data are sufficiently significant in a qualitative sense. At the present stage nothing further is claimed, except that there is scope for more carefully controlled work with less selected samples of larger numbers in differing circumstances, grouped and correlated according to age, sex, refractive error, occupation, intelligence, and " psychological type."

Opportunity has not seriously been taken yet to estimate the part played by anxiety, either in those over-eager but inexperienced or in those of a naturally anxious or obsessional temperament. It . is possibly an important factor, especially if we would construct any hypothesis applicable to the less artificial conditions of everyday life and seek to explain, the development of excessive near point convergence.

Chavasse (Worth's Squint, 7th edition, chapter v) considers that the binocular attitude is attained and conditioned by reflex 
devetopment subject to many possible disturrbing influences. It is not reasonable to assume that the ocular phoria at any age is an inelastic constant; it can be affected by emotional disturbances in the sense of esophoria, and even transient (or permanent?) esotropia. In years of presbyopia; physiological needs outweigh emotional effects though the latter may still be determinant especially in those who acquire compensation neurosis and in some women. One must prefer Duke-Elder's statement (Text Book of Ophthalmology, Vol. 1, p. 763) that copvergence is not normally impaired in presbyopes, to the contrary one of Chavasse (p. 174). Why should it be impaired? The decline in power of accommodation is due not to diminished ciliary effort or innervation but to the reduced elasticity of the crystalline lens which fails adequately to respond: A presbyope without his spectacles is, in fact, esophoric at the near point-regardless of his ability to read Jaeger 1 unaided-he needs, and will appreciate, a plus addition-which creates that slight exophoria which leaves scope within the "safety" limits for convergent stimuli, emotional or occupational.

So also will the workman, civilian, or soldier of forty-odd who suffers cranial or even bodily injury, and states that he could "see to read perfectly before"; a claim for the original cost of provision of such spectacles is not so irrelevant as it might at first appear.

\section{Summary}

A short period of exacting close work in special conditions of binocular dissociation is shown to cause a change of a temporary niature in eye muscle balance at the near point $(33 \mathrm{cms}$.) assessed by normal routine methods.

It is implied that the near point muscle balance cannot accurately be stated without reference to manner of use of the eyes preceding the assessment.

If it can be assumed that man is deficient in natural power of voluntary divergence to counteract accommodative esophoria, it follows that in the "resting" state "near-point". exophoria of some degree accompanied by adequate reserve, power of voluntary convergence is desirable for the comfortable performance of sustained close work.

It is further suggested that in some cases temporary disturbance of this balance and of comfortable near-point effort can arise from emotional causes, especially if aroused by close work and related to anxiety about its successful performance. 